\title{
Evidence that lactotrophs do not differentiate directly from somatotrophs during chick embryonic development
}

\author{
Xiaoqin Fu, Shotaro Nishimura ${ }^{1}$ and Tom E Porter ${ }^{2}$ \\ Department of Animal and Avian Sciences, University of Maryland, College Park, Maryland 20742, USA \\ ${ }^{1}$ Department of Animal and Marine Bioresource Sciences, Faculty of Agriculture, Kyushu University, Fukuoka-shi 812-8581, Japan \\ ${ }^{2}$ Molecular and Cell Biology Program, University of Maryland, College Park, Maryland 20742, USA \\ (Requests for offprints should be addressed to T E Porter; Email: TEPorter@umd.edu)
}

\begin{abstract}
It is generally accepted that, in mammals, lactotrophs differentiate from somatotrophs through an intermediate cell type, the mammosomatotroph. However, little information exists about mammosomatotrophs and their relationship with lactotroph development in non-mammalian vertebrates. We reported previously that corticosterone (CORT) can induce both somatotroph and lactotroph differentiation in cultures of chicken embryonic pituitary cells. Our current objectives were to determine the abundance of mammosomatotrophs during chicken pituitary development, to identify mammosomatotrophs during CORT induction of lactotrophs, and to explore whether lactotrophs induced by CORT are derived from somatotrophs. Cells that produced prolactin (PRL) only, growth hormone $(\mathrm{GH})$ only or both hormones simultaneously were detected by three approaches - dual immunofluorescence, a combination of immunofluorescence and immunocytochemistry (ICC), and by ICC using combinations of antibodies to GH and PRL. Mam-
\end{abstract}

mosomatotrophs were not detected between embryonic day (E) 16 and E20, even though lactotrophs increased from nearly absent to greater than $10 \%$ of all pituitary cells during this period. CORT induced more than $10 \%$ of all E13 pituitary cells to produce PRL, while the percentage of mammosomatotrophs remained at less than $1 \%$ of all cells. When cells from the cephalic and caudal lobes of the anterior pituitary were treated separately, CORT increased GH cells in cultures from the caudal lobe. No PRL cells were found in the caudal lobe. In the cephalic lobe, CORT increased lactotrophs, while GH cells were barely detected. In summary, mammosomatotrophs are rare during chicken pituitary development, and CORT does not induce lactotrophs from somatotrophs. These findings indicate that, unlike in mammals, lactotrophs do not differentiate from somatotrophs during chicken embryonic development.

Journal of Endocrinology (2004) 183, 417-425

\section{Introduction}

The anterior pituitary contains five major hormonesecreting cell types. Corticotrophs produce adrenocorticotrophin, gonadotrophs secrete follicle-stimulating hormone and luteinizing hormone, thyrotrophs secrete thyroidstimulating hormone, somatotrophs secrete growth hormone $(\mathrm{GH})$ and lactotrophs secrete prolactin (PRL). Although morphological studies suggest that all of these cell types arise from a progenitor cell type in Rathke's pouch (Dasen \& Rosenfeld 2001), differentiation of the five cell types does not occur at the same time during development. Usually, the first differentiated cell is the corticotroph, followed by differentiation of gonadotrophs, thyrotrophs, somatotrophs, and lactotrophs in that order (Nemeskeri et al. 1988, Simmons et al. 1990, Dubois \& Hemming 1991, Japon et al. 1994).
Our group has used the chicken embryo as a model to study the mechanisms underlying somatotroph and lactotroph differentiation in the anterior pituitary. The chicken is a good model because of the ease of access to the embryo without maternal interactions. In addition, the pattern of pituitary cell differentiation in chickens is comparable to that in mammals (Barabanov 1991). In chickens, somatotrophs first appear between embryonic day (E) 12 and E14 (Porter et al. 1995). Prolactin cells differentiate by E15 to E19 (Harvey et al. 1979, Barabanov 1985, Ishida et al. 1991, Kansaku et al. 1994, Woods \& Porter 1998).

Somatotrophs and lactotrophs belong to the acidophil classification of cells in the pituitary gland. Studies indicate that pituitary acidophils have phenotypic plasticity and are able to alter their hormonal profiles according to the physiological state of the animal (Frawley et al. 1985, 
Leong et al. 1985, Hooghe-Peters et al. 1988, Frawley 1989, Porter et al. 1990, 1991, Pasolli et al. 1994). Much evidence from rats, mice, and humans supports the theory that a portion of lactotrophs differentiate from somatotrophs via mammosomatotrophs during development (Frawley \& Boockfor 1991, Voss \& Rosenfeld 1992, Rhodes et al. 1994). However, there is little information about the appearance of mammosomatotrophs and their relationship with somatotrophs and lactotrophs during chicken development. On the other hand, we have shown that corticosterone (CORT) can induce both somatotroph and lactotroph differentiation in cultures of chicken embryonic pituitary cells (Morpurgo et al. 1997, Dean \& Porter 1999, Bossis \& Porter 2000, 2003, Porter et al. 2001, Bossis et al. 2004, Fu \& Porter 2004). Do the lactotrophs induced by CORT differentiate from somatotrophs via mammosomatotrophs? The purpose of this study was to identify and enumerate mammosomatotrophs during chicken development and to determine whether or not the lactotrophs induced by CORT originate from somatotrophs through mammosomatotrophs.

\section{Materials and Methods}

\section{Primary pituitary cell cultures}

Cell culture reagents were purchased from Gibco Invitrogen (Grand Island, NY, USA). Hormones and other chemicals were obtained from Sigma Chemical Co. (St Louis, MO, USA). CORT was first dissolved in 100\% ethanol to $10^{-3} \mathrm{M}$ and further diluted to the required concentrations with culture medium. Animals used in this study were Avian $\times$ Avian strain chicken embryos purchased from Allen's Hatchery (Seaford, DE, USA). All experiments were approved by the Institutional Animal Care and Use Committee at the University of Maryland. Eggs were incubated in a humidified incubator at $37.5{ }^{\circ} \mathrm{C}$. The pituitary glands were isolated from chicken embryos under a dissecting microscope. Pituitary glands were pooled and then monodispersed as previously described (Woods \& Porter 1998). For experiments presented in Figs $1-3$, three intact pituitary glands were pooled for each age tested in each replicate experiment. For the comparison of caudal lobe and cephalic lobe cells presented in Fig. 4, the caudal and cephalic thirds of the anterior pituitary glands from 12 embryos were dissected in situ within the sella tursica and pooled for each independent replicate experiment. In all experiments, different pools from different embryos were evaluated for each of the replicate experiments, which were performed on different days. One millilitre of pituitary cell suspension $\left(1.5 \times 10^{6}\right.$ cells $\left./ \mathrm{ml}\right)$ in serum-free culture medium (1:1 mixture of Phenol Red-free medium 199 and Ham's F12, supplemented with $0 \cdot 1 \%$ BSA, $5 \mu \mathrm{g} / \mathrm{ml}$ bovine insulin, $5 \mu \mathrm{g} / \mathrm{ml}$ human transferrin, and penicillin/streptomycin) was transferred into each well of a sterile 12 -well tissue culture plate and cultured in a cell culture incubator at $37.5{ }^{\circ} \mathrm{C}$ in a humidified atmosphere of $95 \%$ air and $5 \% \mathrm{CO}_{2}$. The medium was replaced with fresh medium on the third day.

\section{Immunocytochemistry (ICC)}

Cultured pituitary cells or cells immediately after isolation were washed and diluted in Dulbecco's modified Eagle's medium (DMEM) to a concentration of $10^{4}$ cells $/ \mathrm{ml}$. The cells were then attached for $1 \mathrm{~h}$ to the bottom of polyL-lysine-coated 24-well tissue culture plates and fixed with $3.7 \%$ formaldehyde in PBS for $15 \mathrm{~min}$. Cells were then permeabilized with $0 \cdot 1 \%$ Tween-20/0.1\% Triton X-100 for $8 \mathrm{~min}$ and then quenched with $0 \cdot 3 \% \mathrm{H}_{2} \mathrm{O}_{2}$ for $5 \mathrm{~min}$. Cells were then blocked with $1 \%$ normal goat serum for $30 \mathrm{~min}$ at room temperature and incubated with rabbit anti-chicken PRL antiserum (1:8000 in PBS) or rabbit anti-chicken $\mathrm{GH}$ antiserum (1:4000 dilution in PBS) overnight at $4{ }^{\circ} \mathrm{C}$. Cells were further processed using the rabbit VECTASTAIN ABC kit from Vector Laboratories (Burlingame, CA, USA). Finally, PRL- or GH-positive cells were developed by incubating with substrate (VIP kit, Vector Laboratories). The GH and PRL antisera used have been described and validated previously (Lopez et al. 1995, Porter et al. 1995). Data shown are the percentage of PRL- or GH-containing cells among at least 300 cells counted per well. Immunocytochemistry was performed to detect the cells reacting with $\mathrm{GH}$ antiserum only (somatotrophs), PRL antiserum only (lactotrophs) and their mixture (all acidophils). The proportions of immunopositive cells to all pituitary cells were calculated. If bihormonal mammosomatotrophs exist, the putative proportion of mammosomatotrophs can be estimated as follows: $(\%$ of mammosomatotrophs $)=(\%$ of somatotrophs + $\%$ of lactotrophs $)-(\%$ of acidophils $)$.

\section{Double immunostaining}

To detect mammosomatotrophs directly, double immunostaining was performed by combining the ABC method described above (ICC) with immunofluorescence. Pituitary cells were attached to glass slides coated with poly-L-lysine and subjected to ICC using rabbit antichicken PRL antiserum (1:8000), VECTASTAIN ABC kit and VIP substrate (Vector Laboratories). Next, the cells were reacted with mouse anti-chicken GH monoclonal antibody (1:1000), followed with rhodamine-conjugated goat anti-mouse IgG (1:50). This was performed on cells from E18, E19 and E20. The mouse anti-chicken GH monoclonal antibody was generously provided by Dr Luc Berghman, Texas A\&M University, USA and its validation has been reported previously (Berghman et al. 1987, 1988).

\section{Dual labelling immunofluorescence}

Cells were washed and resuspended in DMEM and allowed to attach to the surface of poly-L-lysine-coated 
slides for $1 \mathrm{~h}$ in the cell culture incubator. The cells were fixed in $3.7 \%$ formaldehyde for $20 \mathrm{~min}$ at room temperature, washed $(3 \times 5 \mathrm{~min})$ in PBS, permeabilized in $0 \cdot 1 \%$ Triton X-100/0·1\% Tween 20 for 8 min, and blocked for $1 \mathrm{~h}$ in $5 \%$ normal goat serum at room temperature. Then the slides were incubated in a diluted mixture of two primary antibodies (rabbit anti-chicken PRL antiserum at 1:4000 dilution and monoclonal anti-chicken GH antibody at 1:1000 dilution, diluted in 1\% normal goat serum) overnight at $4{ }^{\circ} \mathrm{C}$ in humidified conditions. The slides were rinsed in PBS $(4 \times 5 \mathrm{~min})$ and in PBS with $0 \cdot 1 \%$ Tween $20(1 \times 10 \mathrm{~min})$. The slides were then incubated in the dark for $1 \mathrm{~h}$ in diluted second antibody solution in $2 \cdot 5 \%$ normal goat serum with $0 \cdot 025 \%$ Tween-20, which was a mixture of rhodamine red-X-conjugated affinity pure goat anti-rat IgG (1:50 dilution) and fluorescein (FITC)conjugated affinity pure goat anti-rabbit IgG (1:100 dilution) (Jackson Immunoresearch Labs, Westgrove, PA, USA). The slides were washed $(3 \times 5 \mathrm{~min})$ in PBS and $(1 \times 5 \mathrm{~min})$ in PBS with $0.05 \%$ Tween-20. After airdrying, the slides were mounted in VECTORSHIELD (Vector Laboratories) and observed under a fluorescence microscope.

\section{Statistical analysis}

Within each replicate experiment, a single percentage of a given cell type was determined across triplicate wells or slides. This single percentage for that replicate experiment was then used in the statistical analysis across the independent replicate experiments of a given study. All percentage data were transformed by taking the $\log$ of the arcsin prior to analysis of variance using the MIXED models procedure of the Statistical Analysis System (SAS, SAS Institute, Cary, NC, USA). All data were from at least three completely separate replicate experiments using pools of pituitary cells from different embryos. Numbers of replicate experiments are provided in the legend for each figure. Differences between treatments were tested using Tukey's Studentized range test and were considered significant at $P<0 \cdot 05$.

\section{Results}

Are the initial lactotrophs during normal development also mammosomatotrophs?

Studies in mammals indicate that the initial lactotrophs also produce GH. Our first set of experiments was designed to determine if this was also the case during chicken embryonic development. Pituitaries from E18, E19 and E20 chicken embryos were dispersed and subjected to ICC for GH and PRL. ICC was performed to detect cells reacting with GH antiserum only (somatotrophs), PRL antiserum only (lactotrophs) and both

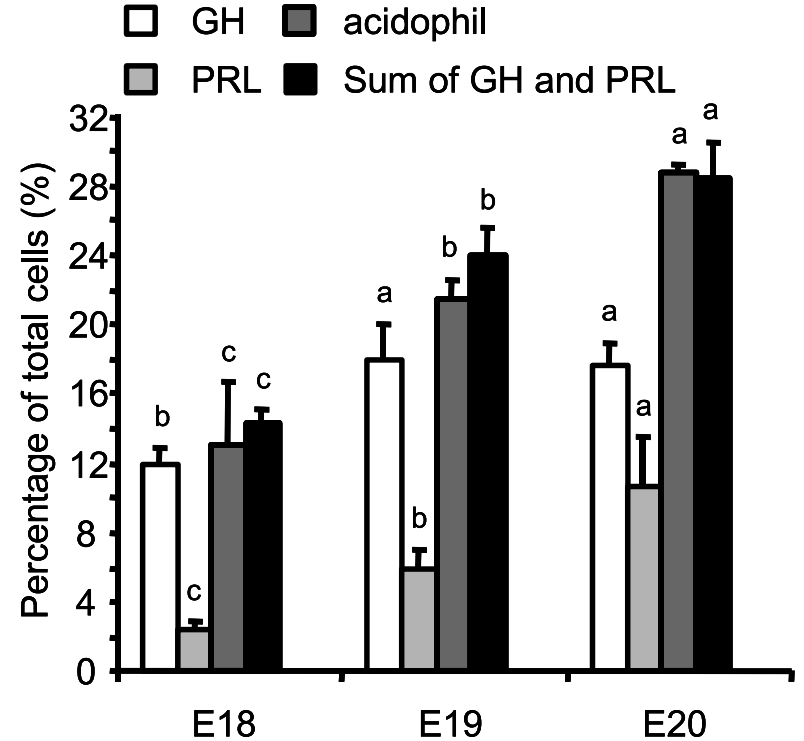

Figure 1 Estimation of lactotrophs, somatotrophs, and total acidophils on E18, E19 and E20. Pituitaries from day 18, 19 and 20 chicken embryos were dispersed, and then ICC was performed to detect cells reacting with $\mathrm{GH}$ antiserum only (somatotrophs), PRL antiserum only (lactotrophs) and either antiserum (total acidophils). The proportions of immunopositive cells among all pituitary cells and the sum of the proportions of lactotrophs and somatotrophs were calculated. Data represent the means \pm S.E.M. of 3 (E18 and E20) or 4 (E19) replicate experiments. Within each ICC analysis (GH only, PRL only, total acidophils, or the sum of $\mathrm{GH}$ and $\mathrm{PRL}$ ) means with different letters are significantly different $(P<0 \cdot 05)$. Within each age, the number of total acidophils was compared with the sum of the GH and PRL cells to test for the presence of mammosomatotrophs. These values were not significantly different at any age tested $(P>0 \cdot 10)$.

antisera in combination (total acidophils). The proportions of immunopositive cells to all pituitary cells were calculated. The proportions of PRL and GH cells and total acidophils were determined directly by ICC. For each replicate experiment and age, the percentage of PRL cells was added to the percentage of GH cells to yield the sum of the PRL and GH cells as a fourth group of results. Percentages of GH cells, PRL cells, total acidophils and the sum of PRL and GH cells were then compared across ages by ANOVA of the results from 3 to 4 replicate experiments for each age. The results are presented in Fig. 1. The percentages of somatotrophs were $12 \cdot 0 \pm 0 \cdot 9 \%$ on E18 $(n=3), 18 \cdot 0 \pm 2 \cdot 1 \%$ on E19 $(n=4)$ and $17 \cdot 7 \pm 1 \cdot 3 \%$ on E20 $(n=3)$. The percentage of $\mathrm{GH}$ immunopositive cells on E19 was significantly larger than that on E18 $(P<0 \cdot 01)$ but not different from that on E20. The proportion of lactotrophs was $2 \cdot 4 \pm 0.5 \%$ on E18 $(n=3)$, $6 \cdot 0 \pm 1 \cdot 1 \%$ on $\mathrm{E} 19(n=4)$ and $10 \cdot 7 \pm 1 \cdot 8 \%$ on $\mathrm{E} 20(n=3)$. The percentage of lactotrophs at each age was different from each of the other ages $(P<0 \cdot 05)$. When pituitary cells were immunostained with $\mathrm{GH}$ and PRL antisera 
simultaneously, the percentages of immunopositive cells (total acidophils) were $13 \cdot 1 \pm 3 \cdot 6 \%$ on E18 $(n=3), 21 \cdot 5 \pm$ $1 \cdot 1 \%$ on E19 $(n=4)$ and $28 \cdot 7 \pm 0.5 \%$ on E20 $(n=3)$. The proportions were significantly different among the stages $(P<0 \cdot 01)$. Within each age, the number of total acidophils was compared with the sum of the PRL and GH cells to test for the presence of mammosomatotrophs. The sum of the GH and PRL cells was not significantly different from the percentage of total acidophils at any age tested $(P>0 \cdot 10)$. These results indicate that cells which contained both GH and PRL, and thus would be counted twice in the summed percentages of individual GH and PRL ICC but only once in ICC using both antisera simultaneously, were not detectable. This finding suggests that mammosomatotrophs were rare or nonexistent in this experiment. To ensure that inclusion of both antibodies did not interfere with the detection of PRL or GH, E20 cells were subjected to ICC with the PRL antiserum alone or in the presence of the GH monoclonal antibody. The proportion of lactotrophs detected with the PRL antiserum alone $(8 \cdot 6 \pm 1 \cdot 6 \%)$ was not different from the results obtained when the GH monoclonal antibody was included $(7 \cdot 7 \pm 0 \cdot 5 \%)$. In a similar analysis in which slides were analysed by double immunostaining, the GH monoclonal antibody and the PRL antiserum reacted to separate cells, and cells reacting to GH and PRL antibodies simultaneously could not be found in any stage examined (data not shown). Co-localization of PRL and GH was also not detected through dual labelling immunofluorescence on E16, E17, E18, E19 and E20 pituitary cells, even though the abundance of lactotrophs increased dramatically during this period. Representative results from triplicate slides in each of 4 replicate experiments on E16, E17, E18, E19 and E20 are shown in Fig. 2A-E. Throughout this analysis of normal development, no cells were found by dual labelling immunofluorescence that contained both $\mathrm{GH}$ and PRL. To confirm that mammosomatotrophs can be detected readily using this technique, we performed dual immunofluorescence for rat GH and PRL on cultured rat pituitary P0 cells. The results are shown in Fig. 2I and J. Consistent with previous reports, all of the PRL cells in the rat $\mathrm{P} 0$ cultures contained $\mathrm{GH}$ or were mammosomatotrophs. Moreover, the abundance of lactotrophs detected in chicken pituitary cells on E20 by immunofluorescence with the PRL antiserum alone $(6 \cdot 3 \pm 1 \cdot 5 \%)$ was not different from that determined in the presence of the $\mathrm{GH}$ monoclonal antibody $(7 \cdot 7 \pm 1 \cdot 9 \%)$. Similarly, the abundance of somatotrophs detected with the GH monoclonal antibody alone $(11.6 \pm 2.5 \%)$ was not different from that determined in the presence of the PRL antiserum $(14 \cdot 7 \pm 2 \cdot 3 \%)$, verifying that the presence of one antibody does not interfere with detection of the heterologous antigen. Taken together, these results indicate that mammosomatotrophs do not exist during the period of chicken embryonic development when lactotrophs differentiate.
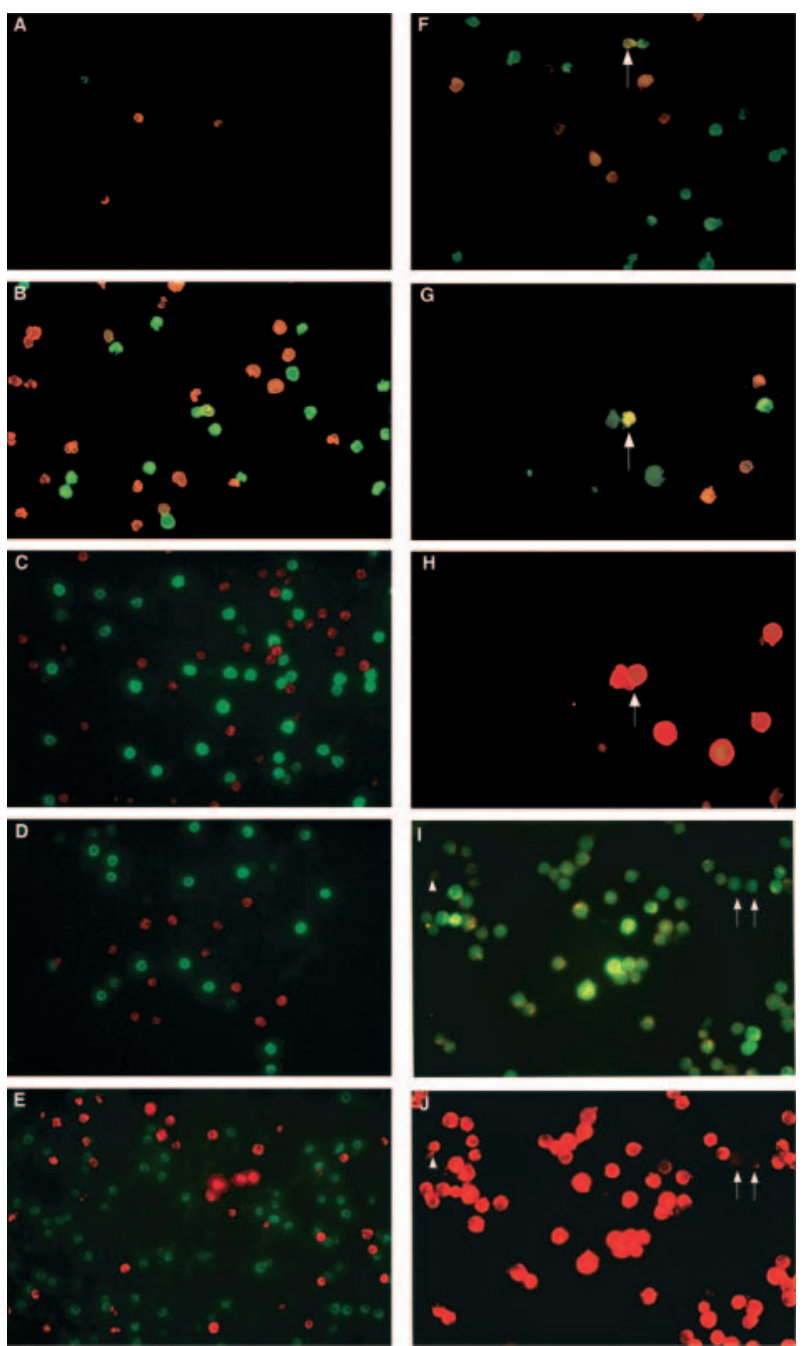

Figure 2 Dual-labelling immunofluorescence of PRL cells and $\mathrm{GH}$ cells. Pituitary cells were isolated from E16 (A), E17 (B), E18 (C), E19 (D) and E20 (E) embryos and immediately subjected to dual-label immunofluorescence for $\mathrm{GH}$ and PRL. GH cells are stained red in $A$ and $B$ and green in C-E. PRL cells are stained green in $\mathrm{A}$ and $\mathrm{B}$ and red in $\mathrm{C}-\mathrm{E}$. The results are representative of triplicate slides performed in each of 4 replicate experiments for each age. $(\mathrm{F}-\mathrm{H})$ E13 pituitary cells were cultured in vitro for 4 days with $10^{-9} \mathrm{M}$ CORT. Cells were viewed under different filters to view green fluorescence ( $F$ and $G$ ) or red fluorescence $(H)$. The results shown in $\mathrm{F}$ indicate most PRL cells (green) and $\mathrm{GH}$ cells (red) were stained separately. Because of the leaking of red fluorescence through the filter used to view green fluorescence, the overall colour of cells stained with both green and red fluorescence is yellow, as indicated by arrows. Panel $\mathrm{H}$ is the same field as in G and shows GH cells stained with red fluorescence. (I and J) The rat pituitary PO cell line was subjected to immunofluorescence for PRL (I) and $\mathrm{GH}(\mathrm{J})$. The results clearly show that nearly all PRL cells also contained GH. Arrows indicate the presence of cells positive for PRL with weak GH staining, and arrowheads indicate cells positive for $\mathrm{GH}$ with weak PRL staining. 
Are there mammosomatotrophs among lactotrophs induced by corticosterone?

We have shown that CORT induces the appearance of PRL-containing lactotrophs and GH-containing somatotrophs in cultures of chicken embryonic pituitary cells. This set of experiments was designed to assess whether the glucocorticoid-induced lactotrophs are in fact mammosomatotrophs. In order to find out whether or not those lactotrophs induced by CORT also produce GH, E13 pituitary cells were cultured in vitro with CORT $\left(10^{-9} \mathrm{M}\right)$ for 4 days. PRL- and GH-containing cells were detected with dual labelling immunofluorescence on day 4 (Fig. 2F-H). Monoclonal anti-chicken GH antibody and rabbit anti-chicken PRL antiserum were used. Then rhodamine red-X-conjugated affinity-purified goat antirat IgG and FITC-conjugated affinity-purified goat antirabbit IgG were used to show GH cells and PRL cells respectively. In Fig. 2F, nearly all PRL cells and GH cells were stained separately. Only one cell, indicated by an arrow, was stained with both red and green fluorescence, leading to an overall yellow colour. Fig. $2 \mathrm{G}$ shows PRL cells stained with green fluorescence. Fig. $2 \mathrm{H}$ is the same field as in Fig. $2 \mathrm{G}$ and shows GH cells stained with red fluorescence. Arrows in $\mathrm{G}$ and $\mathrm{H}$ show one mammosomatotroph that was labelled with both green and red fluorescence, also leading to an overall yellow colour shown in Fig. $2 \mathrm{G}$. In order to determine the percentage of mammosomatotrophs induced by CORT, the percentage of PRL cells, GH cells, and mammosomatotrophs were counted (Fig. 3). Consistent with our previous report (Fu \& Porter 2004), CORT significantly increased the percentages of both lactotrophs and somatotrophs. No mammosomatotrophs were detected in cells from untreated cultures. In CORT-treated cultures, the percentage of mammosomatotrophs among all pituitary cells was $0.98 \pm$ $0 \cdot 85 \%(n=3)$. Consequently, some mammosomatotrophs among the lactotrophs induced by CORT do exist, but the percentage of mammosomatotrophs is very low.

Do corticosterone-induced lactotrophs and somatotrophs arise from the same precursor population of cells?

The anterior pituitary in birds can be anatomically divided into two regions, the cephalic and caudal lobes. In adult birds, lactotrophs are mainly located in the cephalic lobe of the anterior pituitary, while somatotrophs are mainly localized in the caudal lobe of the anterior pituitary (Hansen \& Hansen 1977, Jozsa et al. 1979, Mikami 1986, Thommes et al. 1987, Berghman et al. 1992, Lopez et al. 1995, Ramesh et al. 1996). In order to determine from where the glucocorticoid-induced lactotrophs and somatotrophs arise, cephalic and caudal lobe cells from E13 embryos were cultured separately for 1 and 4 days with or without CORT $\left(10^{-9} \mathrm{M}\right)$. The cells were then subjected to ICC for GH or PRL. Results are shown in Fig. 4.

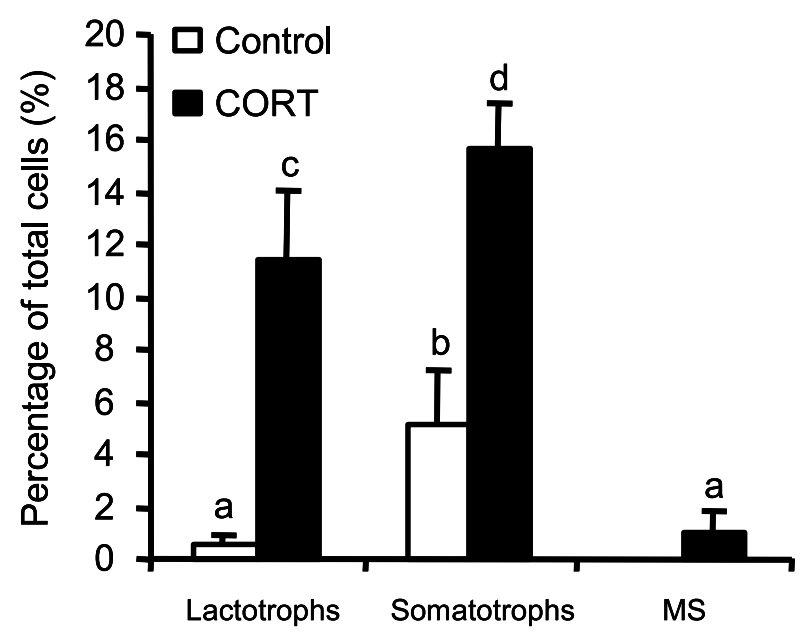

Figure 3 The percentages of lactotrophs, somatotrophs, and mammosomatotrophs (MS) found in cultured embryonic pituitary cells. E13 pituitary cells were cultured in vitro with medium alone (control) or with $10^{-9}$ M CORT for 4 days. Dual labelling immunofluorescence was used to detect GH-containing cells and PRL-containing cells simultaneously. The percentages of red fluorescence-labelled $\mathrm{GH}$ cells or green fluorescence-labelled PRL cells in total cells were counted under a fluorescence microscope. Cells labelled with both red fluorescence and green fluorescence were defined as MS. The percentage of MS in total PRL-containing cells was determined with a fluorescence microscope. Then the percentage of MS in total cells was calculated based on the percentage of PRL cells in total cells. Data represent the means \pm S.E.M. of 3 replicate experiments. Means with different letters are significantly different $(P<0 \cdot 05)$.

CORT significantly increased the proportions of $\mathrm{GH}-$ containing cells $(24 \pm 4 \%)$ relative to control $(7 \pm 1 \%$, $n=3)$ in cultures from the pituitary caudal lobe after one day of treatment. No PRL-containing cells were found in the caudal lobe, even after four days of incubation with CORT. In the cephalic lobe cell cultures, CORT significantly increased the proportions of lactotrophs after four days of treatment $(12 \pm 1 \%)$ relative to control $(1 \pm 0 \cdot 1 \%$, $n=3, P<0 \cdot 05)$. No response was found after one day of treatment. GH cells were barely detected in the cephalic lobe. The results clearly demonstrate that CORT-induced PRL cells and GH cells result from different precursor cell populations located in the cephalic and caudal lobes respectively.

\section{Discussion}

It is generally accepted that, in mammals, lactotrophs arise from somatotrophs or a common precursor cell type during development. This theory is supported by evidence from studies in rats, humans, mice and other species. In rats, the appearance of lactotrophs occurs around birth and approximately one week after GH cell differentiation. Using a sequential plaque assay, Hoeffler et al. (1985) analysed the 
proportions of mammosomatotrophs and single hormone secretors, which either secrete GH or PRL, present in neonatal day 5 pituitaries. Their results indicated that about $36 \%$ of acidophils were mammosomatotrophs, but

\section{Caudal Lobe}

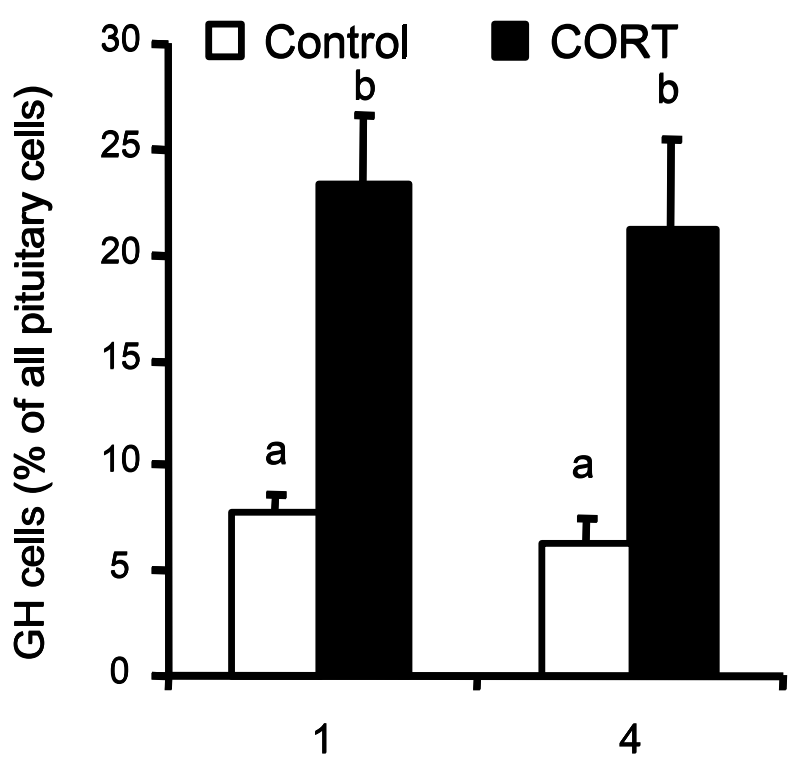

Treatment time (days)

\section{Cephalic Lobe}

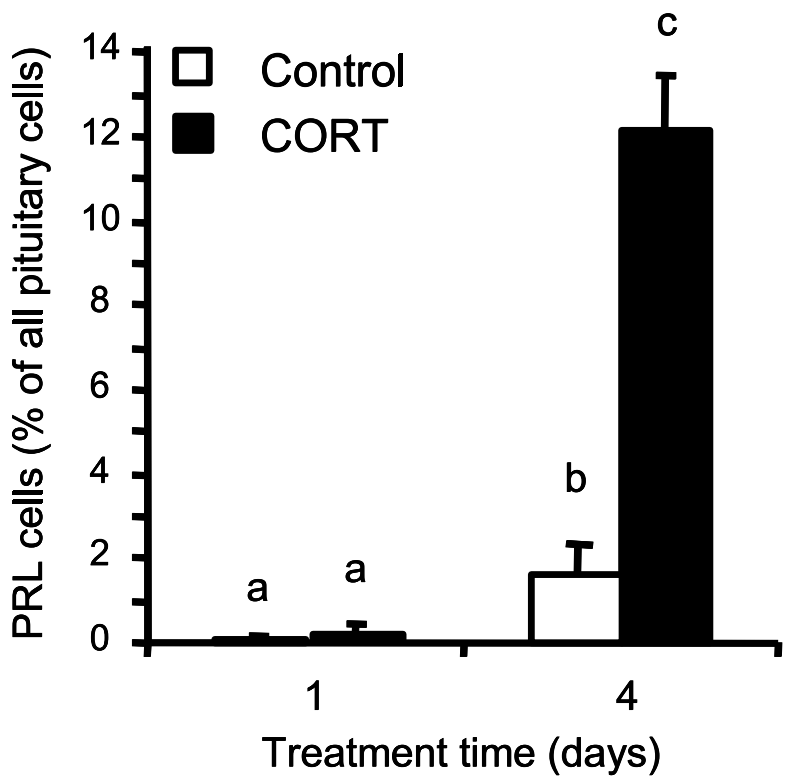

less than $2 \%$ of all acidophils secreted PRL only. Consequently, they concluded that almost all of the initial PRL cells in rats are mammosomatotrophs. A subpopulation of $\mathrm{GH}$ cells was found at or before birth that only secreted GH but contained PRL mRNA (Hooghe-Peters et al. 1988). In humans, PRL cells appear at least 1 month later than the initial appearance of GH cells. Mulchahey \& Jaffe (1988) performed sequential plaque assays on human fetal pituitary cells (aged 18-22 weeks) and found that about $22 \%$ of acidophils were mammosomatotrophs, while less than $9 \%$ of acidophils were PRL only cells. Therefore, more than two-thirds of the PRL-secreting cells are mammosomatotrophs at that age in humans. The strongest evidence supporting the idea that lactotrophs differentiate from somatotrophs was provided from transgenic mice studies (Behringer et al. 1988, Borrelli et al. 1989). In transgenic mice with targeted ablation of $\mathrm{GH}$ cells during fetal development, the lactotroph population was also nearly abolished, indicating that the majority of lactotrophs arise directly from $\mathrm{GH}$-expressing cells. On the other hand, a small population of PRL cells remained in those transgenic mice lacking GH cells, suggesting that a small proportion of lactotrophs arises from non-GH producing acidophils. Despite this compelling evidence, there exists contrasting evidence not supporting the theory. In fetal mice, a few pituitary cells express both GH and PRL mRNA, but the majority of PRL mRNA-expressing cells did not express GH mRNA (Dolle et al. 1990). Shirasawa et al. (1990) did not detect mammosomatotrophs in fetal bovine pituitary glands. In fetal rats, PRL cells were mainly present in the anterior half of the pituitary, whereas $\mathrm{GH}$ cells were predominantly present in its posterior half, and the mirror section technique revealed that PRL and GH were contained in different cells (Watanabe \& Haraguchi 1994). In neonatal rats, the percentage of mammosomatotrophs reported by Takahashi (1995) was not as high as that reported by Hoeffler et al. (1985). These differences from studies in rats and mice may be due to the different age, sex and physiological status of the animals used, and the different techniques used. Despite this conflicting evidence from rats and mice, many current models describing anterior pituitary development still support the theory that lactotrophs arise from somatotrophs or at least a common progenitor cell (Frawley \& Boockfor 1991, Voss \& Rosenfeld 1992, Rhodes et al. 1994, Asa 2001, Dasen \& Rosenfeld 2001, Burgess et al. 2002, Scully \& Rosenfeld 2002).

Figure 4 Responses of cephalic and caudal lobe anterior pituitary cells to CORT in vitro. Cells from the cephalic and caudal lobes of E13 embryonic anterior pituitaries were cultured separately for 1 and 4 days with or without CORT $\left(10^{-9} \mathrm{M}\right)$. The cells were then subjected to ICC for GH or PRL. PRL-containing cells and $\mathrm{GH}$-containing cells were rare in the caudal and cephalic lobes respectively (not shown). Data represent the means \pm S.E.M. of 3 replicate experiments. Means with different letters are significantly different $(P<0 \cdot 05)$. 
However, the situation in non-mammalian vertebrates might be different. Different somatotroph and lactotroph localizations were found in most non-mammalian vertebrates (Porter \& El Halawani 2001). For example, in one reptile studied (Chalcides chalcides), PRL cells were clustered in the rostral anterior pituitary and in the medial anterior pituitary. Somatotroph cells were found in the caudal anterior pituitary (Ferrandino et al. 2001). As mentioned before, the anterior pituitary in birds can also be anatomically divided into two regions, the cephalic and caudal lobes. Lactotrophs are mainly located in the cephalic lobe, while somatotrophs are mainly localized in the caudal lobe of the anterior pituitary (Hansen \& Hansen 1977, Jozsa et al. 1979, Mikami 1986, Thommes et al. 1987, Berghman et al. 1992, Lopez et al. 1995, Ramesh et al. 1996). Based on these findings, we hypothesized that mammosomatotroph cells might not exist during chick embryonic development, and lactotroph cells may not differentiate from cells producing GH. In order to detect the existence of mammosomatotrophs during chick development, pituitaries from chicken embryos of three ages, E18, E19 and E20, were subjected to ICC and double immunostaining for GH and PRL. Our current data show that mammosomatotrophs are not detected during this developmental period in the chicken. Dual labelling immunofluorescence also failed to detect mammosomatotrophs on E16, E17, E18, E19 or E20. Our results indicate that the initial lactotrophs to develop in the chicken do not also produce $\mathrm{GH}$. This observation does not support a role for mammosomatotrophs as an intermediate cell type during normal lactotroph differentiation.

Our previous results demonstrated that CORT could not only induce somatotroph differentiation in vivo and in vitro (Morpurgo et al. 1997, Dean \& Porter 1999, Bossis \& Porter 2000, Porter et al. 2001, 2003, Bossis et al. 2004), but could also induce lactotroph differentiation in pituitary cell cultures (Fu \& Porter 2004). Induction of lactotrophs by CORT in vitro requires at least three days, whereas CORT treatment for as short as $16 \mathrm{~h}$ increases the percentage of GH cells (Porter et al. 2001). Therefore, lactotroph induction needs longer CORT exposure compared with somatotroph induction by CORT. Based on the theory that lactotrophs arise from somatotrophs, our next question addressed whether those lactotrophs induced by CORT are derived from the somatotrophs induced by CORT. Results from dual immunofluorescence indicated that the vast majority of PRL cells and GH cells induced by CORT were distinctly separate, and very few cells contained both hormones. The percentage of potential mammosomatotrophs was less than $1 \%$ of all cells. No mammosomatotrophs were detected in the control cultures. Consequently, lactotrophs induced by CORT are not mammosomatotrophs nor are they likely to be derived from somatotrophs.

Current dogma holds that lactotrophs differentiate from somatotrophs or a common precursor cell type during development, at least in mammals. We have shown that glucocorticoids can induce the appearance of lactotrophs as well as somatotrophs in chicken embryonic pituitary cell cultures, consistent with a common developmental mechanism and lineage for somatotroph and lactotroph differentiation. However, lactotrophs and somatotrophs reside at opposite ends of the anterior pituitary, suggesting that lactotrophs may not differentiate directly from somatotrophs in non-mammalian vertebrates. Our present study addressed whether glucocorticoid-induced lactotrophs and somatotrophs arise from a common precursor population. To pursue this question, we cultured anterior pituitary caudal lobe and cephalic lobe cells separately. Our hypothesis was that lactotrophs induced by CORT arise in the cephalic lobe, while somatotrophs induced by CORT arise in the caudal lobe. Our results confirmed our hypothesis. Nearly all somatotrophs induced by CORT were found in caudal lobe cell cultures, and lactotrophs induced by CORT were found exclusively in cephalic lobe cell cultures. Furthermore, CORT induction of both lactotrophs and somatotrophs was not influenced by the separate culture of cephalic lobe and caudal lobe cells. Therefore, the presence of somatotrophs was not necessary for CORT induction of lactotrophs and vice versa. These results clearly indicate that somatotrophs and lactotrophs arise from separate precursor cell populations, residing in the caudal lobe and cephalic lobe, respectively, of the chick anterior pituitary gland.

Our current investigation indicates that mammosomatotrophs are nonexistent during normal chicken pituitary development and are rare among PRL and GH cells induced by CORT. However, all of our studies tested for the presence of PRL and GH within the same cell at one point in time. Thus, it is possible that cellular GH content was too low to detect or was lost before PRL was induced within the same cell. However, we do not favour these possibilities. Regarding sensitivity of GH and PRL detection in the current study, we showed that CORT induced expression of both GH- and PRL-containing cells to readily detectable levels. Yet, the two hormones remained expressed almost exclusively in separate cells. This would suggest that the lack of mammosomatotrophs during development was not due to poor sensitivity of the techniques used. Regarding the possibility that GH production is turned off prior to initiation of PRL synthesis, we found that CORT induced both $\mathrm{GH}$ and PRL production but in different lobes and in different cells. Lactotrophs induced by CORT were found in the cephalic lobe of the anterior pituitary and were not derived from somatotrophs induced by CORT, which were found in the caudal lobe. The caudal and cephalic lobe cells were isolated on day 13 of embryonic development, before large numbers of either cell type differentiate. Thus, our present findings do not support the possibility that early somatotrophs present in the caudal lobe of the chick anterior pituitary migrate into the cephalic lobe and cease 
producing $\mathrm{GH}$ before differentiating into lactotrophs, because somatotrophs and lactotrophs were induced among caudal and cephalic lobe cells cultured separately. However, it remains possible that GH and PRL cells arise from a common precursor cell during development that produces neither hormone. Subpopulations of this precursor cell population may migrate to the caudal and cephalic lobes of the anterior pituitary, where GH and PRL gene expression is induced respectively. We conclude that lactotrophs do not differentiate directly from somatotrophs during avian embryonic development.

\section{Funding}

This research was supported by grant No. 03-03520612836 from the USDA-NRI competitive grants programme.

\section{References}

Asa SL 2001 Transgenic and knockout mouse models clarify pituitary development, function and disease. Brain Pathology 11 371-384.

Barabanov VM 1985 Immunohistochemical detection of prolactin in the hypophysis of the chick and chick embryo. Ontogenez 16 118-126.

Barabanov VM 1991 Determination of adenohypophysis cytodifferentiation during embryonic development. Ontogenez 22 175-181.

Behringer RR, Mathews LS, Palmiter RD \& Brinster RL 1988 Dwarf mice produced by genetic ablation of growth hormone-expressing cells. Genes and Development 2 453-461.

Berghman LR, Lens P, Decuypere E, Kuhn ER \& Vandesande F 1987 Glycosylated chicken growth hormone. General and Comparative Endocrinology 68 408-414.

Berghman LR, Van Beeumen J, Decuypere E, Kuhn ER \& Vandesande F 1988 One step purification of chicken growth hormone from a crude pituitary extract by use of a monoclonal immunoadsorbent. Journal of Endocrinology 118 381-387.

Berghman LR, Grauwels L, Vanhamme L, Proudman JA, Foidart A, Balthazart J \& Vandesande F 1992 Immunocytochemistry and immunoblotting of avian prolactins using polyclonal and monoclonal antibodies toward a synthetic fragment of chicken prolactin. General and Comparative Endocrinology 85 346-357.

Borrelli E, Heyman RA, Arias C, Sawchenko PE \& Evans RM 1989 Transgenic mice with inducible dwarfism. Nature 339 538-541.

Bossis I \& Porter TE 2000 Ontogeny of corticosterone-inducible growth hormone-secreting cells during chick embryonic development. Endocrinology 141 2683-2690.

Bossis I \& Porter TE 2003 Evaluation of glucocorticoid-induced growth hormone gene expression in chicken embryonic pituitary cells using a novel in situ mRNA quantitation method. Molecular and Cellular Endocrinology 201 13-23.

Bossis I, Nishimura S, Muchow M, \& Porter TE 2004 Pituitary expression of type I and type II glucocorticoid receptors during chicken embryonic development and their involvement in growth hormone cell differentiation. Endocrinology 145 3523-3531.

Burgess R, Lunyak V \& Rosenfeld MG 2002 Signaling and transcriptional control of pituitary development. Current Opinion in Genetics and Development 12 534-539.

Dasen JS \& Rosenfeld MG 2001 Signaling and transcriptional mechanisms in pituitary development. Annual Review of Neuroscience 24 327-355.
Dean CE \& Porter TE 1999 Regulation of somatotroph differentiation and growth hormone $(\mathrm{GH})$ secretion by corticosterone and GH-releasing hormone during embryonic development. Endocrinology 140 1104-1110.

Dolle P, Castrillo JL, Theill LE, Deerinck T, Ellisman M \& Karin M 1990 Expression of GHF-1 protein in mouse pituitaries correlates both temporally and spatially with the onset of growth hormone gene activity. Cell 60 809-820.

Dubois PM \& Hemming FJ 1991 Fetal development and regulation of pituitary cell types. Journal of Electron Microscopy Technique 19 2-20.

Ferrandino I, Viscardi G \& Grimaldi MC 2001 An immunohistochemical study of adenohypophyseal cells in the viviparous reptile Chalcides chalcides. Histochemical Journal 33 1-8.

Frawley LS 1989 Mammosomatotropes: current status and possible functions. Trends in Endocrinology and Metabolism 1 31-34.

Frawley LS \& Boockfor FR 1991 Mammosomatotropes: presence and functions in normal and neoplastic pituitary tissue. Endocrine Reviews $12337-355$.

Frawley LS, Boockfor FR \& Hoeffler JP 1985 Identification by plaque assays of a pituitary cell type that secretes both growth hormone and prolactin. Endocrinology 116 734-737.

Fu X \& Porter TE 2004 Glucocorticoid induction of lactotrophs and prolactin gene expression in chicken embryonic pituitary cells: a response delayed relative to stimulated growth hormone production. Endocrinology 145 1322-1330.

Hansen GN \& Hansen BL 1977 Light and electron microscopic identification of pituitary cells containing growth hormone and prolactin in the pigeon (Columba livia), using the immunoglobulin-enzyme bridge technique. General and Comparative Endocrinology 32 99-107.

Harvey S, Davison TF \& Chadwick A 1979 Ontogeny of growth hormone and prolactin secretion in the domestic fowl (Gallus domesticus). General and Comparative Endocrinology 39 270-273.

Hoeffler JP, Boockfor FR \& Frawley LS 1985 Ontogeny of prolactin cells in neonatal rats: initial prolactin secretors also release growth hormone. Endocrinology 117 187-195.

Hooghe-Peters EL, Belayew A \& Herregodts P 1988 Discrepancy between prolactin (PRL) messenger ribonucleic acid and PRL content in rat fetal pituitary cells: possible role of dopamine. Molecular Endocrinology 2 1163-1168.

Ishida H, Shimada K, Sato K, Seo H, Murata Y, Matsui N \& Zadworny D 1991 Developmental expression of the prolactin gene in the chicken. General and Comparative Endocrinology 83 463-467.

Japon MA, Rubinstein M \& Low MJ 1994 In situ hybridization analysis of anterior pituitary hormone gene expression during fetal mouse development. Journal of Histochemistry and Cytochemistry 42 $1117-1125$.

Jozsa R, Scanes CG, Vigh S \& Mess B 1979 Functional differentiation of the embryonic chicken pituitary gland studied by immunohistological approach. General and Comparative Endocrinology 39 158-163.

Kansaku N, Shimada K, Terada O \& Saito N 1994 Prolactin, growth hormone, and luteinizing hormone- $\beta$ subunit gene expression in the cephalic and caudal lobes of the anterior pituitary gland during embryogenesis and different reproductive stages in the chicken. General and Comparative Endocrinology 96 197-205.

Leong DA, Lau SK \& Sinha YN 1985 Enumeration of lactotropes and somatotropes among male and female pituitary cells in culture: evidence in favor of a mammosomatotrope subpopulation in the rat. Endocrinology 116 1371-1378.

Lopez ME, Hargis BM, Dean CE \& Porter TE 1995 Uneven regional distributions of prolactin- and growth hormone-secreting cells and sexually dimorphic proportions of prolactin secretors in the adenohypophysis of adult chickens. General and Comparative Endocrinology 100 246-254.

Mikami S 1986 Immunocytochemistry of the avian hypothalamus and adenohypophysis. International Review of Cytology 103 189-248. 
Morpurgo B, Dean CE \& Porter TE 1997 Identification of the blood-borne somatotroph-differentiating factor during chicken embryonic development. Endocrinology 138 4530-4535.

Mulchahey JJ \& Jaffe RB 1988 Detection of a potential progenitor cell in the human fetal pituitary that secretes both growth hormone and prolactin. Journal of Clinical Endocrinology and Metabolism $\mathbf{6 6}$ 24-32.

Nemeskeri A, Setalo G \& Halasz B 1988 Ontogenesis of the three parts of the fetal rat adenohypophysis. A detailed immunohistochemical analysis. Neuroendocrinology 48 534-543.

Pasolli HA, Torres AI \& Aoki A 1994 The mammosomatotroph: a transitional cell between growth hormone and prolactin producing cells? An immunocytochemical study. Histochemical Journal 102 287-296.

Porter TE \& El Halawani ME 2001 Regulation of lactotrophs and prolactin secretion in non-mammalian vertebrates. In Prolactin, pp. 63-79. Ed N Horseman. Boston, MA: Kluwer Academic Publishers.

Porter TE, Hill JB, Wiles CD \& Frawley LS 1990 Is the mammosomatotrope a transitional cell for the functional interconversion of growth hormone- and prolactin-secreting cells? Suggestive evidence from virgin, gestating, and lactating rats. Endocrinology 127 2789-2794.

Porter TE, Wiles CD \& Frawley LS 1991 Evidence for bidirectional interconversion of mammotropes and somatotropes: rapid reversion of acidophilic cell types to pregestational proportions after weaning. Endocrinology 129 1215-1220.

Porter TE, Couger GS, Dean CE \& Hargis BM 1995 Ontogeny of growth hormone $(\mathrm{GH})$-secreting cells during chicken embryonic development: initial somatotrophs are responsive to GH-releasing hormone. Endocrinology 136 1850-1856.

Porter TE, Dean CE, Piper MM, Medvedev KL, Ghavam S \& Sandor J 2001 Somatotroph recruitment by glucocorticoids involves induction of growth hormone gene expression and secretagogue responsiveness. Journal of Endocrinology 169 499-509.
Ramesh R, Proudman JA \& Kuenzel WJ 1996 Changes in pituitary somatotroph and lactotroph distribution in laying and incubating turkey hens. General and Comparative Endocrinology 104 67-75.

Rhodes SJ, DiMattia GE \& Rosenfeld MG 1994 Transcriptional mechanisms in anterior pituitary cell differentiation. Current Opinion in Genetics and Development 4 709-717.

Scully KM \& Rosenfeld MG 2002 Pituitary development: regulatory codes in mammalian organogenesis. Science 295 2231-2235.

Shirasawa N, Hirano M \& Ishikawa H 1990 Immunocytochemistry of mammotroph and somatotroph in fetal and adult bovine pituitary by three different methods. Jikeikai Medical Journal 37 433-446.

Simmons DM, Voss JM, Ingraham HA, Holloway JM, Broide RS, Rosenfeld MG \& Swanson LW 1990 Pituitary cell phenotypes involve cell-specific Pit-1 mRNA translation and synergistic interactions with other classes of transcription factors. Genes and Development 4 695-711.

Takahashi S 1995 Development and heterogeneity of prolactin cells. International Review of Cytology 157 33-98.

Thommes RC, Umporowicz DM, Leung FC \& Woods JE 1987 Ontogenesis of immunocytochemically demonstrable somatotrophs in the adenohypophyseal pars distalis of the developing chick embryo. General and Comparative Endocrinology 67 390-398.

Voss JW \& Rosenfeld MG 1992 Anterior pituitary development: short tales from dwarf mice. Cell 70 527-530.

Watanabe YG \& Haraguchi H 1994 Immunohistochemical study of the cytogenesis of prolactin and growth hormone cells in the anterior pituitary gland of the fetal rat. Archives of Histology and Cytology 57 161-166.

Woods KL \& Porter TE 1998 Ontogeny of prolactin-secreting cells during chick embryonic development: effect of vasoactive intestinal peptide. General and Comparative Endocrinology 112 240-246.

Received in final form 21 July 2004

Accepted 26 July 2004

Made available online as an Accepted Preprint

10 August 2004 